\title{
Market-oriented Operations Strategy of CCHP with Multiple Models
}

\author{
Xi Wang ${ }^{1}$, Wei Wang ${ }^{1}$, Hao Xu ${ }^{1}$, Qiang Ye ${ }^{1}$, Shi Chen ${ }^{2}$ and Chuyun $\mathrm{Jia}^{2 *}$ \\ ${ }^{1}$ State Grid Sichuan Economic Research Institute, Chengdu, Sichuan, 610064, China \\ ${ }^{2}$ Chengdu Hiway Electric Power Technology Consulting, Chengdu, Sichuan, 610064, China
}

\begin{abstract}
In this paper, the Market-oriented Operations Strategy of CCHP are analysed, from the perspective of construction mode, operating mode and charging mode. On this basis, a three-dimensional indexes system is established, and combining the entropy weight method with Analytic Hierarchy Process as a comprehensive evaluation method to evaluate the different market-oriented strategies of CCHP. Finally, the empirical analysis of the commercial building in southwest China shows that the market-oriented strategy of CCHP can bring more benefits to market participants when it has high applicability and great practical value.
\end{abstract}

\section{Introduction}

As the issues of energy, climate and environment become more and more serious, energy conservation and reduction of carbon emissions are widely concerned by countries around the world. Therefore, the system of Combined Cooling, Heating and Power (CCHP) which fueled by natural gas has been actively developed.

In recent years, based on numerous research results of mature system physical models, the system of CCHP has been promoted and applied worldwide[1-5]. At the same time, in the field of electrical economics research, it is imperative to study market-oriented operations strategy of CCHP and establish an operations strategy framework to further adapt to current market operations[6-8].

Based on existing research, the operations strategy of CCHP is analyzed in this paper, from the point of contractors(including equipment installation sellers, operating service providers), investors, users and other stakeholders(utility companies)[9].With an empirical analysis of the cooling \& heating load of a commercial building in southwest China, two typical operation strategies are compared, which provided a basis for the formulation of the market expansion of CCHP.

\section{Basic performance of physical model of CCHP}

The schematic of a redundant system of CCHP driven by electrical and gaseous energy is shown as figure 1, in which there are two energy supply schemes for each of cooling, heating and power loads. Once one system fails, the other can still continue to supply energy, that reflects the concept of redundancy and complementary energy use.

The meaning of the variables in figure 1 is represented in table 1 , and the thermodynamic equilibrium constraints and the electric power balance constraints in CCHP can be obtained as shown in equations (2.1) (2.2), respectively.

$$
\begin{aligned}
& E_{\text {plant }}+P E_{\text {drive }} \eta_{\text {drive }}=E_{\text {cold }}+E \\
& Q_{\text {recycle }}+Q_{\text {boiler }}=Q_{\text {out }}+Q_{\text {reheat }}+Q_{\text {recold }}
\end{aligned}
$$

The maximum area method is used for CCHP capacity allocation according to equations (2.3) (2.4). In figure .2, the abscissa is the running time of the system, and the ordinate is the load (heat, electricity). Therefore, the physical significance of points A and B is that when the capacity is determined by this point, the driving equipment of the system can operate at full load to the maximum in the whole year, which is simple and effective.

$$
\begin{aligned}
& \left(x_{A} \times y_{A}\right)=\left.\max (x \times y)\right|_{(x, y) \in A} \\
& \left(x_{B} \times y_{B}\right)=\left.\max (x \times y)\right|_{(x, y) \in B}
\end{aligned}
$$

Point $B$ under grid-combined mode satisfies the limitation of power balance. While point A under feed-in mode has low equipment cost and high heat utilization efficiency.

\footnotetext{
*Corresponding author's e-mail: 478880550@qq.com
} 


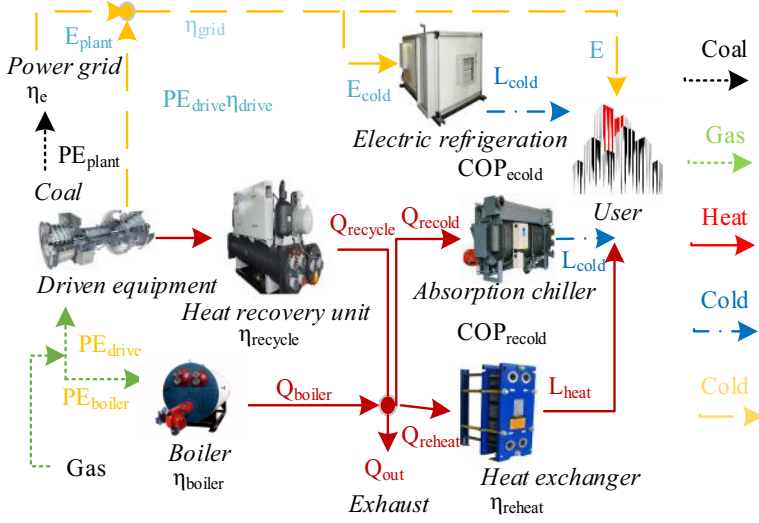

Figure 1. Schematic of CCHP system.

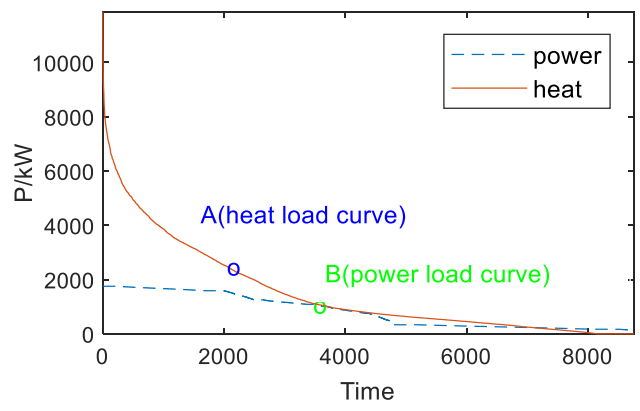

Figure 2. Load delay curve of office buildings in southwest China.

Table 1. The meaning of the variables in Figure 1

\begin{tabular}{cl|cl}
\hline \multicolumn{1}{c|}{ Nomenclature } & \multicolumn{1}{c}{ Subscript } \\
\hline$P E$ & primary energy & plant & power plant \\
$Q$ & heat & drive drive equipment of CCHP \\
$E$ & electricity & boiler & supplementary combustion boiler \\
$L$ & heating or cooling load & recycle heat recovery device \\
$C O P$ & coefficient of performance & ecold electric refrigeration equipment \\
$\eta$ & efficiency & recold & absorption refrigeration equipment \\
& & reheat & heat exchanger \\
& & out & exhaust gas emissions \\
\hline
\end{tabular}

\section{Operating model framework of CCHP}

The research method of market-oriented operation strategy of CCHP incorporates the game mechanism of power market in electrical engineering. Furthermore, the operation situations of existing projects of CCHP were investigated and analyzed, from which the operating model framework of CCHP was built systematically, as shown in figure $3[6]$.
Construction mode mainly refer to investing and financing choice of energy companies, including solutions to the problems of fund raising, management and ownership of CCHP projects.

Operation mode refers to the connection between CCHP and the power grid according to load forecasting, commissioning requirements and equipment capacity, etc.

Charge mode is the way to users' trade with energy companies. It enables investment recovery and impacts the formulation and implementation of operational strategies.
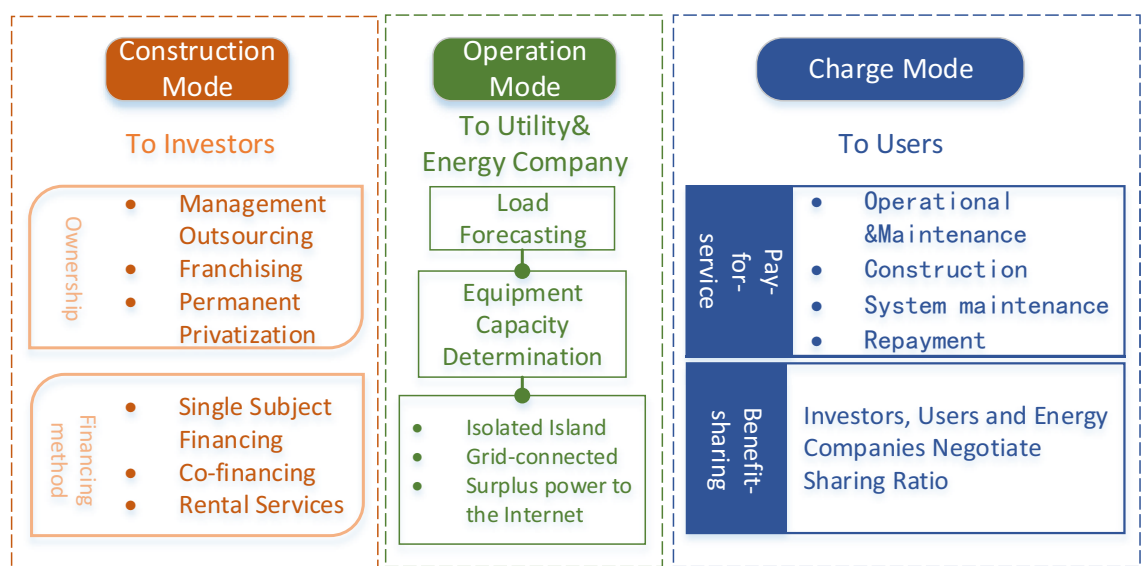

Figure 3. Operations Strategy Modes of CCHP 


\section{Comprehensive evaluation method of CCHP}

In order to optimize the combination of multiple modes of CCHP, a hierarchical indexes evaluation system was established, as shown in table 2.

Table 2. Indexes System of CCHP

\begin{tabular}{lll}
\hline \multicolumn{1}{c}{ First-level } & \multicolumn{1}{c}{ Second-level(AHC) } & \multicolumn{1}{c}{ Third-level(Entropy Method) } \\
\hline & & Initial Investment $\left(U_{I 1}\right)$ \\
Scheme & Economic Feasibility $\left(U_{1}\right)$ & $\operatorname{NPV}\left(U_{12}\right)$ \\
Feasibility & & $\operatorname{IRR}\left(U_{13}\right)$ \\
Index & & Payback Period $\left(U_{14}\right)$ \\
\cline { 2 - 3 }$T$ & \multirow{2}{*}{ Technical Feasibility $\left(U_{2}\right)$} & $\operatorname{PESR}\left(U_{21}\right)$ \\
& & System Safety Assessment $\left(U_{22}\right)$ \\
\cline { 2 - 3 } & Environmental Protection & Environmental Cost of $\mathrm{CO}_{2}\left(U_{31}\right)$, \\
& Feasibility $\left(U_{3}\right)$ & $\mathrm{SO}_{2}\left(U_{32}\right), \mathrm{NO}_{\mathrm{x}}\left(U_{33}\right)$ \\
\hline
\end{tabular}

\subsection{Economic feasibility index $\left(U_{1}\right)$}

Initial investment cost, annual operating cost and annual benefit, as essential basic parameters, should be prepared before analyzing the payback period (PP), net present value (NPV) and internal rate of return (IRR), according to equations $(4.1) \sim(4.3)$.

$$
\begin{gathered}
U_{12}=\sum_{t=1}^{n} \frac{N C F_{t}}{\left(1+i_{c}\right)^{t}}-U_{11} \\
{\left[\left(\sum_{t=1}^{n} \frac{R-C}{\left(1+i_{c}\right)^{t}}\right) \times \frac{i_{c}\left(1+i_{c}\right)^{n}}{\left(1+i_{c}\right)^{n}-1}\right]^{*} \sum_{t=0}^{n}\left(1+\mathrm{U}_{13}\right)^{-t}=0} \\
U_{14}=m-1+\frac{\left|\sum_{t=0}^{m-1} N C F_{t}\left(1+i_{c}\right)^{-t}\right|}{N C F_{m}\left(1+i_{c}\right)^{-m}}
\end{gathered}
$$

Where $N C F_{t}$ is net cash flow $(N C F)$ for the given year; $n$ is service life of CCHP; $i_{c}$ is the discount rate; $R$ is annual income; $m$ represents the year when the cumulative value of NCF is positive.

\subsection{Technical feasibility index $\left(\mathrm{U}_{2}\right)$}

High utilization rate of primary energy and excellent equipment performance are necessary conditions to get a higher primary energy saving rate (PESR), shown as equation (4.4), for the technical feasibility indexes of a $\mathrm{CCHP}$ project. Since equipment configuration and operation technology need to be vigorously developed and upgraded, for low operation risk.

$$
U_{21}=\frac{\left(1 / \eta_{1}-1 / \eta_{2}\right) \times\left(L_{\text {cold }}+L_{\text {cold }}+E\right)}{\frac{E+L_{\text {cold }} / C O P_{\text {ecold }}}{\eta_{e} \eta_{\text {grid }}}+\frac{L_{\text {heat }}}{\eta_{\text {boiler }} \eta_{\text {reheat }}}}
$$

Where $\eta_{1}$ is resource utilization rate of separate system, while $\eta_{2}$ is that for CCHP.

In the design phase, the size, location and capacity of the CCHP should be fully considered as they will affect the stability of the connected grid. And this is why the System Safety Assessment (SSA) indicator is used for technical feasibility assessment. As for its evaluation method, the expert scoring method is adopted here, and the corresponding qualitative evaluation is carried out according to the experience and suggestions of relevant experts.

\subsection{Environmental protection feasibility index $\left(\mathrm{U}_{3}\right)$}

In the system of CCHP, the driving equipment and the boiler are respectively burned by natural gas and coal as raw materials, and the generated pollutant gas must be filtered by the exhaust gas control system before being discharged. The environmental protection feasibility is represented by the following indexes[9-11].

$$
U_{3, p}=\omega_{p}\left\{0.01\left[\alpha_{p}+\beta_{p} P(\mathrm{t})+\gamma_{p} P^{2}(\mathrm{t})\right]+\varepsilon_{p} \exp \left[\lambda_{p}\right]\right\}
$$

Where $U_{3, p}$ is the environmental protection feasibility index of polluted gas, $p ; \omega_{p}$ is the environmental treatment cost; $\alpha_{p} 、 \beta_{p} 、 \gamma_{p} 、 \varepsilon_{p} 、 \lambda_{p}$ are capacity emission parameters, and $P(\mathrm{t})$ is real-time load in $\mathrm{t}$ (hour).

\subsection{Comprehensive evaluation method of CCHP}

The operational strategy of CCHP can provide a reference for investment direction, while meeting basic energy needs.

In terms of evaluation methods, the indexes system shown in table 2 is characterized by clear structures, while containing some excessive subjectivities. Therefore, each index is quantized to a value between -1 and 1 firstly, and then weighted by entropy weighting (EWM)/analytic hierarchy process (AHP) to make full use of the advantages of the two methods. Finally, based on users' load data, comprehensive evaluation and sequencing of each business model is performed.

After the comprehensive assessment, the income of market participants should be considered. Because only the benefits of the parties are within a reasonable range, 
the company's business models can meet the reequipment of Pareto efficiency and ensure the active participation of all parties.

Among the market participants, users, project contractors and investors agree on the profit-sharing ratio according to the requirements of different business models, or users pay the fixed service fee according to the

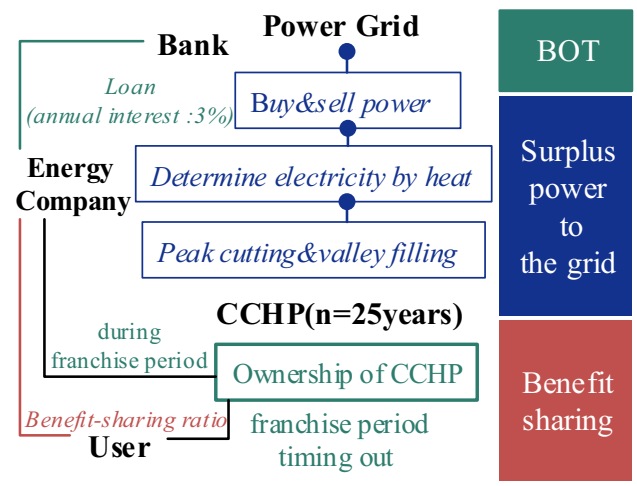

Figure 4. Typical model 1.

\section{Examples}

The performance of CCHP system of commercial office buildings in southwest China is analysed as in figure 2, under the two typical models as figure 4 and figure 5 .

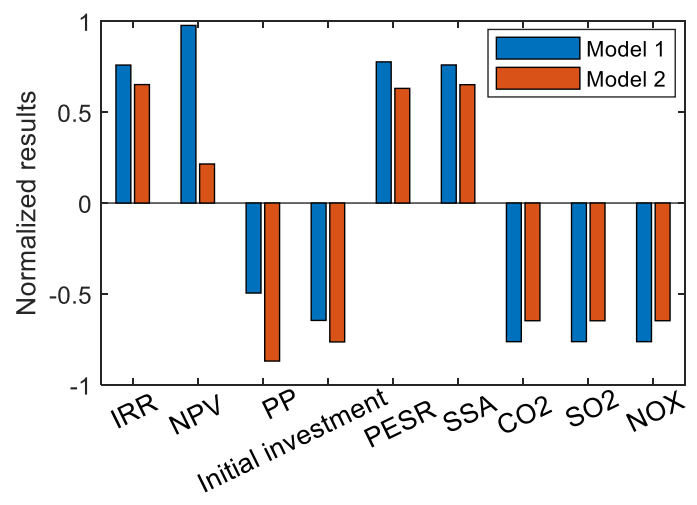

Figure 6. Indicators of CCHP under two Models

Economic feasibility takes the most weighted set in figure 7. This result emphasizes the importance of profitability in operational strategy of CCHP, and encourages technologies' development of "open source and throttling".

The demand of heat rather than the balance of energy needs to be considered in model 1 . On the one hand, there are lower requirements for equipment capacity than model 2. On the other hand, electricity purchase cost and environmental cost are higher. agreement. For power grid, CCHP delays the investment of power grid construction and reduces the loss of transmission and distribution, but it also brings the risk of power grid's stability, as well as reducing the revenue from electricity sales [12]. The balance point should be sought.

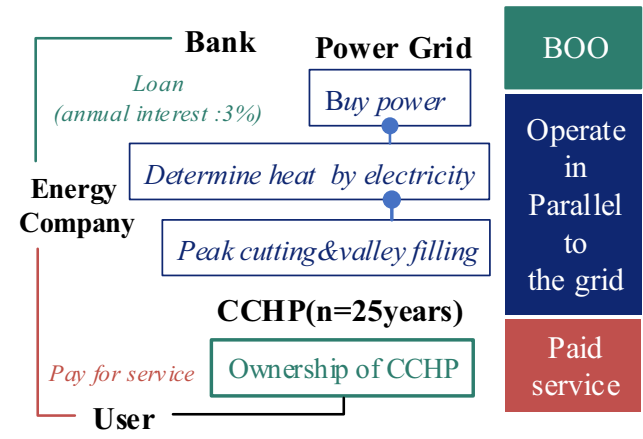

Figure 5. Typical model 2.

\subsection{Analysis of multi-index quantitative results of CCHP}

The comprehensive evaluation indexes' results under model 1 and model 2 are 0.234490523 and 0.034621264 , respectively. Indicators under two models are shown as figure 6 .

Figure 7. Distribution of Annual Benefits.

The dynamic payback periods of mode 1 and model 2 are both within the life span of CCHP, satisfying the requirements of feasibility of construction. At the same time, the investment conditions are satisfied (IRR $>0$ and NPV $>0$ ). However, due to the negative value of results under model 2, the application condition is failed, indicating that the comprehensive evaluation method of CCHP can fully reflect the suitability of operation strategy. 


\subsection{Analysis of the participants}

Under model 1, after repayment period of the first five years, the energy benefit sharing ratio of contractors and users are $74.685 \%$ and $25.315 \%$.

Energy Corporation takes larger risks as well as getting more energy earnings. In the early stage of operating period, income of CCHP are mainly used to carry on the capital recovery of contractors. After that, users will enjoy more energy-saving benefits.

Energy-saving benefit for users isn't a big amount in the early lifetime of CCHP. But it grows larger in the later stage of the project, as investor stopping earning. Because investment is proportional to the benefit sharing ratio during the franchise period, the ratio of the investor is higher, correspondingly.

Although the power grid does not directly participate in benefit sharing, its benefits are affected by the change of power loads. Under the constraint condition of the balance of interests of power grid, the threshold of unit investment cost of power grid is $\beta>0.824(Y /(\mathrm{kWh} /$ year $))$

\section{Conclusion}

On the basis of physical and economic data of the project of CCHP, suitable solutions of operational strategy can be found. This will support CCHP projects to further adapt to the market-oriented environment.

The main conclusions are as follows:

(1) Sales and profits are important in enhancing the competitiveness of CCHP projects, but the choice of operations strategy of CCHP should be based on the guarantee of environmental safety.

(2) Financing in model 1 is mainly finished by energy company, so higher income is obtained by energy company, accordingly. This is consistent with the principle that the higher risk-taking side of the electricity market has higher returns.

(3) Price factor, discount rate factor and loan term have great influence on the indicators. The stability of energy prices should be strictly controlled, as it's related to the lifeblood of electricity market operation.

(4) For a specific load, it is necessary to select an operations strategy with great practical value among various models, in order to achieve better benefits for each market participant. The proposed CCHP indexes system in this paper can be used to rank business models, while considering the multi-dimensional comprehensive performance of CCHP.

\section{Acknowledgments}

This work was supported in part by the State Grid Sichuan Economic Research Institute.

\section{References}

1. Chao Q, Dong X, Jiang D. (2018) Optimization Planning of Integrated Electricity-Gas Community
Energy System Based on Coupled CCHP. Power System Technology, 42:2456-2466

2. Munkhammar J, Grahn P, Widen J. (2013) Quantifying self-consumption of on-site photovoltaic power generation in households with electric vehicle home charging. Solar Energy, 97:206-216

3. ASCE (2011) NewsBriefs: DOE Funds Energy Efficiency Advances(U.S. Department of Energy). Civil Engineering-asce, 73:30.

4. Wu Q, et al. (2014) Multi-criteria assessment of combined cooling, heating-power systems located in different regions in Japan. Applied Thermal Engineering, 73:658-668

5. Ebrahimi, Masood, S. Majidi. (2017) Exergy-energyenviron evaluation of combined cooling heating and power system based on a double stage compression regenerative gas turbine in large scales. Energy Conversion and Management,150:122-133

6. Zeng M, et al. (2013) Key Economic Issues in Integrated Energy System. East China Electric Power,41:1403-1408

7. Kong X, Wang R, Huang X. (2003) Energy efficiency and economic feasibility of CCHP driven by stirling engine. Energy Conversion and Management,45:1433-1442

8. Kosaka, Michitaka, T. Yabutani. (2012) A Service Business Model for Saving Energy and Reduction of $\mathrm{CO} 2$ Emissions Using Inverters. Electrical Engineering in Japan, 179:40-48

9. Wang Z, et al. (2018) Research on the business model of electric energy substitution. Power Demand Side Management, 113:43-45

10. Ran X, et al. (2013) Environmental economic dispatch considering equal emission performance coefficient for CCHP. Electric Power Automation Equipment,33:94-99

11. Qian K. (2008) Environmental Benefits Analysis of Distributed Generation. Proceedings of CSEE, 29:1115

12. Wang $T$ (2016) The Project Study on Energy Performance Contract of Distributed Energy. North China Electric Power University. 